
p.233-237, abr-jun 2005 .

\title{
Associação de densidades populacionais de cenoura e alface no desempe- nho agronômico da cenoura em cultivo consorciado em faixa
}

\author{
Francisco Bezerra Neto; Aurélio P. Barros Júnior; Maria Zuleide de Negreiros; Eliane Q. de Oliveira; \\ Lindomar Maria da Silveira; Maria José T. Câmara \\ ESAM, C. Postal: 59625-900 Mossoró-RN; E-mail: bezerra@esam.br.
}

\section{RESUMO}

O experimento foi realizado de junho a setembro de 2003, em área experimental da ESAM, para avaliar associações de densidades populacionais de cenoura e alface no desempenho agronômico da cenoura em sistema consorciado em faixa. O delineamento experimental utilizado foi de blocos completos casualizados, em esquema fatorial 4 x 4 com cinco repetições. Os tratamentos foram resultantes da combinação de quatro populações de cenoura [100\%; 80\%; $60 \%$ e $40 \%$ população recomendada no cultivo solteiro (PRCS)] com quatro populações de alface (100\%; $80 \% ; 60 \%$ e $40 \%$ da PRCS). A PRCS da cenoura na região é de 500.000 plantas/ha e no cultivo da alface é de 250.000 plantas/ha. As cultivares de cenoura e alface plantadas, pertencentes aos grupos Brasília e Americana, foram, respectivamente, 'Brasília' e 'Tainá'. Na cenoura avaliou-se altura de plantas, massa seca da parte aérea e das raízes, produtividades total e comercial, e classificação de raízes. Não houve interação significativa entre as densidades populacionais da cenoura e de alface em qualquer uma das características avaliadas na cenoura. Não houve também efeito significativo do aumento dos níveis populacionais da alface em qualquer característica avaliada na cenoura. $\mathrm{O}$ aumento na densidade populacional da cenoura aumentou a altura de plantas da cenoura e diminui a massa seca da parte aérea e de raízes, e a percentagem de raízes classes longa e média, e refugo. O aumento na associação das densidades populacionais de cenoura e de alface aumentou a produtividade total e comercial da cenoura, além do aumento na percentagem de raízes classe curta.

Palavras-chave: Daucus carota, Lactuca sativa, produção, qualidade de raízes.

\begin{abstract}
Association of carrot and lettuce planting densities on carrot agronomic performance in strip-intercropping system

An experiment was carried out from June to September 2003, in the field, in Mossoró, Rio Grande do Norte State, Brazil. Associations of carrot (cv. Brasília) and lettuce (cv. Tainá) planting densities on carrot agronomic performance in strip-intercropping system were evaluated. The experimental design was of randomized complete blocks in a $4 \times 4$ factorial scheme with five replications. The treatments of the factorial consisted of the combination of four carrotplanting densities $[100 \% ; 80 \%$; $60 \%$ and $40 \%$ of the recommended sole crop density (RSCD)] with four lettuce-planting densities (100\%; $80 \%$; $60 \%$ and $40 \%$ of the RSCD). The recommended planting density for the sole crop in the region is of 500.000 plants/ha for carrot and 250.000 plants/ha for lettuce. From the carrot crop we evaluated the plant height, shoot and root dry mass, total and commercial yield and classification of roots. No significant interaction between carrot densities and lettuce densities for any assessed trait in carrot crop was obtained. Also, no significant effect of increase in lettuce density was observed for any carrot-assessed trait. Plant height increased as carrot planting density increased, whereas shoot and root dry mass, and percentage of long and mean, and refused roots decreased with increasing of carrot density. As the association of carrot and lettuce planting densities increased, the total and commercial yield and percentage of short roots increased.
\end{abstract}

Keywords: Daucus carota, Lactuca sativa, yield, root quality.

(Recebido para publicação em 16 de fevereiro de 2004 e aceito em 25 de janeiro de 2005)

$\mathrm{D}$ iversos autores abordam a importância de sistemas consorciados, tanto como peça fundamental na manutenção de pequenas propriedades agrícolas em países subdesenvolvidos, quanto como componente de sistemas agrícolas mais sustentáveis (FRANCIS, 1986). A ocorrência de consórcios em diversas regiões indica que o número de interações ecológicas presentes nos agroecossistemas pode ser muito maior que os considerados nos modelos de agricultura convencional, em que a avaliação econômica, mais do que a biológica, determina os padrões de eficiência (SANTOS, 1998).

A importância de muitos fatores que influenciam as decisões de manejo nes- tes sistemas ainda não tem sido estudada a contento e nem tem suas interações múltiplas sido quantificadas sucessivamente pela pesquisa. Neste contexto, encontra-se o cultivo da cenoura e alface, hortaliças estas de boa expressão econômica e nutricional.

Alguns aspectos dos sistemas consorciados cenoura e alface, tais como cultivares e arranjos de plantio, têm sido estudados, porém fatores como associação de densidades populacionais das culturas componentes ainda não têm sido abordados neste tipo de consórcio. Saldanha et al. (2001), avaliando o desempenho de quatro cultivares de alface crespa consorciada com cenoura cv.
Brasília, em dois arranjos de plantio em faixas (três fileiras de alface alternadas com três fileiras de cenoura e quatro fileiras de alface alternadas com quatro fileiras de cenoura), verificaram que os rendimentos totais de raízes de cenoura foram maiores quando estava consorciada com as cultivares de alface Tainá e Lucy Brown, e semelhantes em ambos os arranjos de plantio.

Bezerra Neto et al. (2001), avaliando o valor agroeconômico do consórcio alface do grupo lisa e cenoura cv. Brasília em dois sistemas de cultivos em faixas (três fileiras de cenoura alternadas com três fileiras de alface e quatro fileiras de cenoura alternadas com qua- 


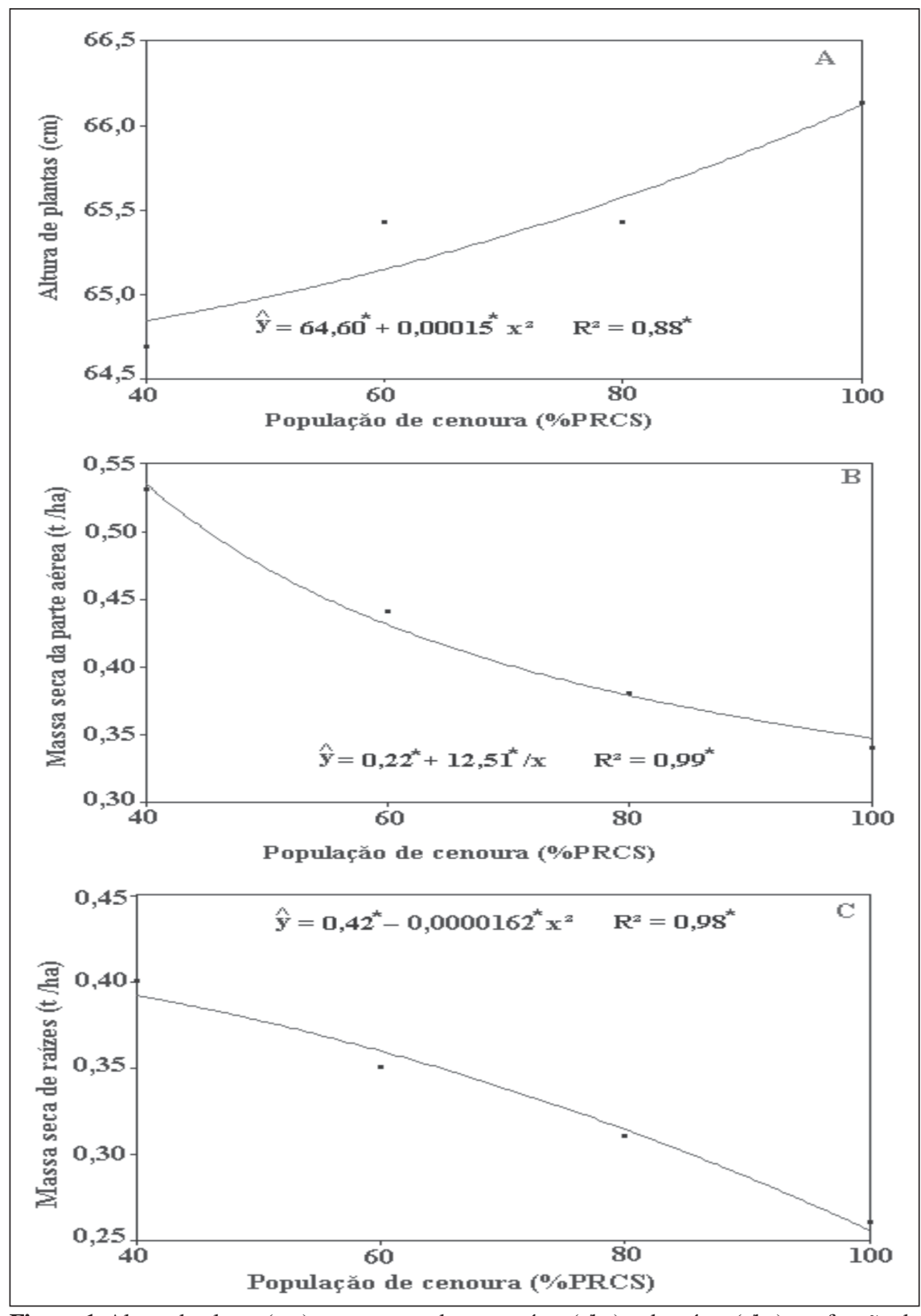

Figura 1. Altura de planta (cm), massa seca da parte aérea (t/ha) e de raízes (t/ha) em função de densidades populacionais de cenoura e alface em sistema consorciado. Mossoró, ESAM, 2003.

tro fileiras de alface), verificaram que o arranjo em faixas com quatro fileiras foi o que apresentou maior viabilidade econômica.

As propostas de espaçamento e densidade de plantio, para as culturas em geral, têm procurado atender às necessidades especificas dos tratos culturais e a melhoria da produtividade. Todavia, alterações nestes fatores induzem uma série de modificações no crescimento e no desenvolvimento das plantas e precisam ser conhecidas com maiores detalhes (SOUZA, 1996).
Visando obter subsídios para o desenvolvimento de tecnologias de produção para a cenoura em associação com alface, o presente trabalho visa avaliar associações de densidades populacionais de cenoura e alface no desempenho agronômico da cenoura em sistema consorciado em faixa.

\section{MATERIAL E MÉTODOS}

$\mathrm{O}$ experimento foi realizado em campo da ESAM, de junho a setembro de 2003, em um Argissolo Vermelho
Amarelo Eutrófico. As características do solo da área experimental foram: $\mathrm{pH}$ (água 1:2,5) =8,49; $\mathrm{Ca}=7,12 \mathrm{cmol} \mathrm{dm}^{-3}$;

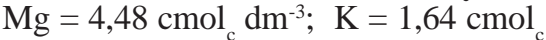
$\mathrm{dm}^{-3} ; \mathrm{Na}=0,24^{\mathrm{c}} \mathrm{cmol} \mathrm{dm}^{-3} ; \mathrm{Al}=0,00^{\mathrm{c}}$ $\mathrm{cmol}_{\mathrm{c}} \mathrm{dm}^{-3}$ e $\mathrm{P}=382,7 \mathrm{mg} \mathrm{dm}{ }^{-3}$.

O município de Mossoró está situado a $5^{\circ} 11^{\prime}$ de latitude $\mathrm{S}$ e $37^{\circ} 20^{\prime}$ 'de longitude WGr e altitude de $18 \mathrm{~m}$. O clima da região segundo Thornthwaite é semiárido e de acordo com Köppen é BSwh', seco e muito quente, com duas estações climáticas: uma seca, de junho a janeiro, e uma chuvosa, de fevereiro a maio.

$\mathrm{O}$ delineamento experimental utilizado foi de blocos casualizados completos com cinco repetições, sendo os tratamentos arranjados em esquema fatorial $4 \times 4$. Os tratamentos resultaram da combinação de quatro populações de plantas de cenoura [40\%; 60\%; $80 \%$ e $100 \%$ da população recomendada no cultivo solteiro (PRCS)] com quatro populações de plantas de alface (40\%, 60\%, $80 \%$ e $100 \%$ da PRCS). O nível populacional recomendado no cultivo solteiro da cenoura na região é de 500.000 plantas/ha (Siqueira, 1995) e no cultivo da alface de 250.000 plantas/ha (SILVA, 1999).

Cada parcela no sistema consorciado foi constituída de duas faixas com quatro fileiras (uma de cenoura e outra de alface). A bordadura constituiu-se de uma fileira em cada lado da parcela. A área total da parcela foi $1,92 \mathrm{~m}^{2}$, com uma área útil de $1,60 \mathrm{~m}^{2}$. O espaçamento de plantio, bem como o número de plantas na área útil, variaram de acordo com cada nível populacional em cada combinação entre as populações de cenoura e alface.

A cultivar de cenoura usada foi a Brasília, pertencente ao grupo Brasília, indicada para a região nordeste (VIEIRA et al.,1983). Ela apresenta folhagem verde escura, raízes cilíndricas com coloração laranja-clara e baixa incidência de ombro verde ou roxo, resistente ao calor, à requeima por Alternaria e ao pendoamento prematuro. A cultivar de alface utilizada foi a Tainá, do grupo americana, indicada para o mercado de consumo fresco, devido ao excelente sabor. Caracteriza-se pela alta capacidade produtiva, tamanho grande de cabeças, boa formação de ombro e alta resistência ao pendoamento precoce (Sementes Sakama, 2002). 
Foi realizada uma solarização na área de plantio, durante 60 dias, para evitar ou reduzir a população de fitopatógenos do solo, que viessem prejudicar a produtividade da cultura da cenoura. Durante a condução do experimento, foram efetuadas capinas manuais e irrigação pelo sistema de microaspersão.

Nos canteiros de plantio, foram realizadas a adubação orgânica com 80 t/ ha de esterco de bovino e a química com $40 \mathrm{~kg} / \mathrm{ha}$ de nitrogênio, na forma de uréia, $60 \mathrm{~kg} / \mathrm{ha}$ de $\mathrm{P}_{2} \mathrm{O}_{5}$, na forma de superfosfato simples e $30 \mathrm{~kg} / \mathrm{ha}$ de $\mathrm{K}_{2} \mathrm{O}$, na forma de cloreto de potássio, de acordo com a análise realizada no solo.

Foram realizadas duas adubações nitrogenadas em cobertura na cenoura, aos 25 e aos 45 dias após o plantio com $40 \mathrm{~kg} / \mathrm{ha}$ de nitrogênio na forma de uréia. Junto com a primeira adubação em cobertura nitrogenada, foi realizada paralelamente uma adubação potássica de $30 \mathrm{~kg} / \mathrm{ha}$ de $\mathrm{K}_{2} \mathrm{O}$.

A alface foi semeada em dois cultivos sucessivos, em 30/05 e 08/08/2003, em copos descartáveis de $150 \mathrm{ml}$, contendo como substrato comercial uma mistura de fibra de coco e composto orgânico na proporção de 1:2. Foram semeadas três a cinco sementes por recipiente e aos três dias após a germinação efetuou-se o primeiro desbaste, deixando-se duas plântulas/recipiente, e aos oito dias o segundo desbaste, deixandose apenas uma plântula/recipiente. As mudas foram produzidas sob sombreamento, utilizando-se uma estufa coberta com plástico branco leitoso. As mudas de alface do primeiro cultivo foram transplantadas para as faixas adjacentes da cenoura aos 24 dias após a semeadura, e as do segundo cultivo aos 18 dias após a semeadura, quando a cenoura se encontrava com 11 e 75 dias da semeadura, respectivamente.

A cenoura, cultura principal, foi semeada em 12/03/2003. O desbaste foi realizado 25 dias após a semeadura, deixando-se apenas uma planta a cada $0,05 \mathrm{~m}$

A colheita da cenoura foi realizada em 08/09/2003, com um ciclo de 88 dias após o plantio. Foram avaliados a altura de plantas, massa seca da parte aérea e das raízes, produtividade total (obtida do peso das raízes das plantas da área útil, e expressa em t/ha), comercial (obtida do

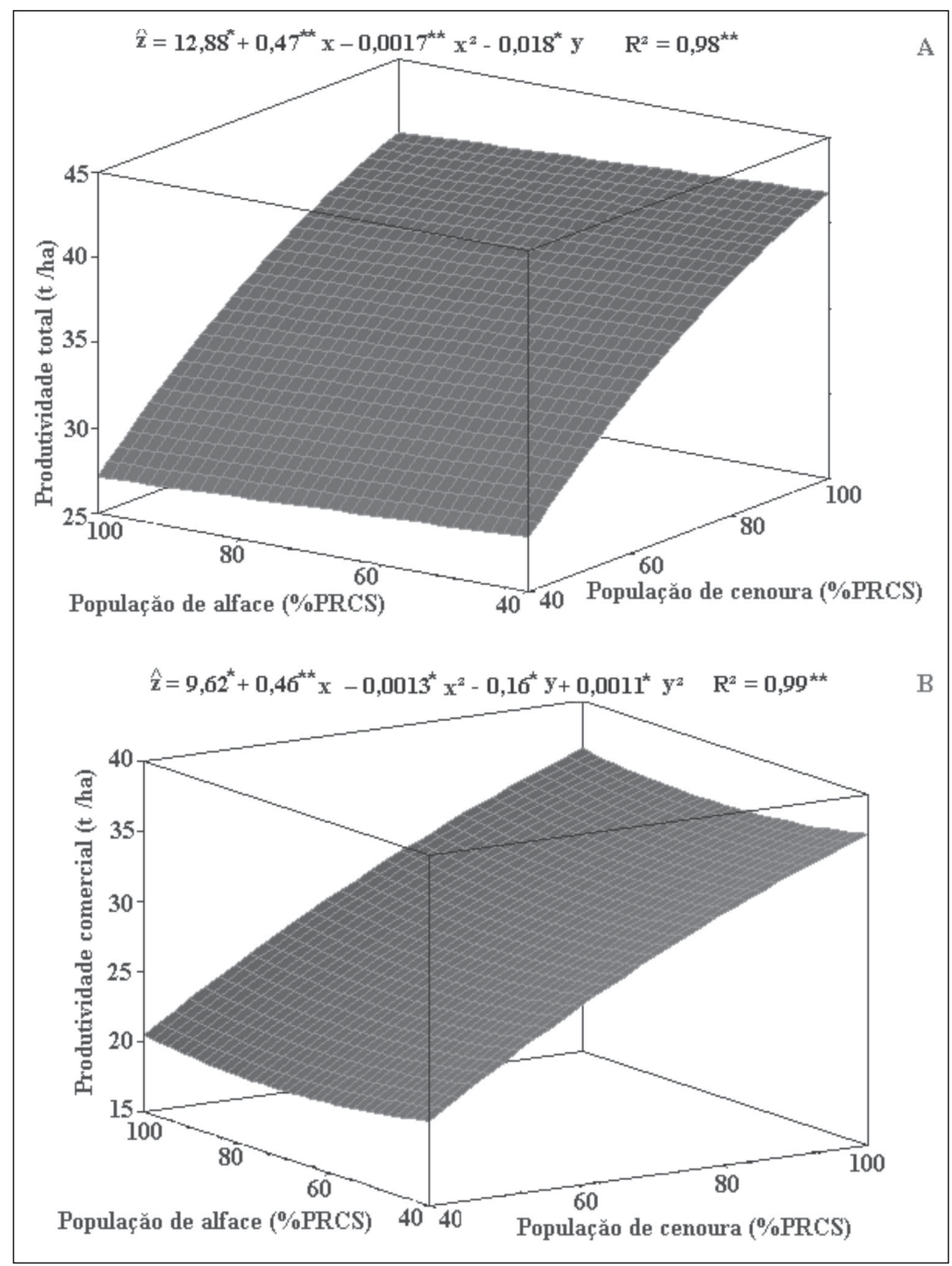

Figura 2. Produtividade total e comercial ( $t /$ ha) de diferentes densidades populacionais de cenoura e alface em sistema consorciado. Mossoró, ESAM, 2003.

peso das raízes das plantas da área útil, livres de defeitos como rachaduras, bifurcações, nematóides e danos mecânicos e expressa em t/ha) e classificação de raízes (longas, com comprimento de 17 a $25 \mathrm{~cm}$ e diâmetro menor que $5 \mathrm{~cm}$; médias, com comprimento de 12 a $17 \mathrm{~cm}$ e diâmetro maior que $2,5 \mathrm{~cm}$; curtas, com comprimento de 5 a $12 \mathrm{~cm}$ e diâmetro maior que $1 \mathrm{~cm}$; e refugo, raízes que não se enquadram nas medidas anteriores, conforme Vieira et al. (1997).

Uma análise de variância univariada para o delineamento de blocos casualizados em esquema fatorial foi utilizado para avaliar as características da cenoura, através do software SPSS/
PC (NORUSIS, 1990). Os efeitos dos fatores densidades populacionais foram avaliados pelos procedimentos de ajustamento de curvas de resposta através do software Table Curve Package (JANDEL SCIENTIFIC, 1991).

\section{RESULTADOS E DISCUSSÃO}

Não houve interação significativa entre as populações de cenoura e de alface em nenhuma das características avaliadas na cenoura (Figuras 1, 2 e 3). Porém, para cada uma das características avaliadas na cenoura, testou-se um ajustamento de uma superfície de resposta ou de uma curva de regressão simples em 


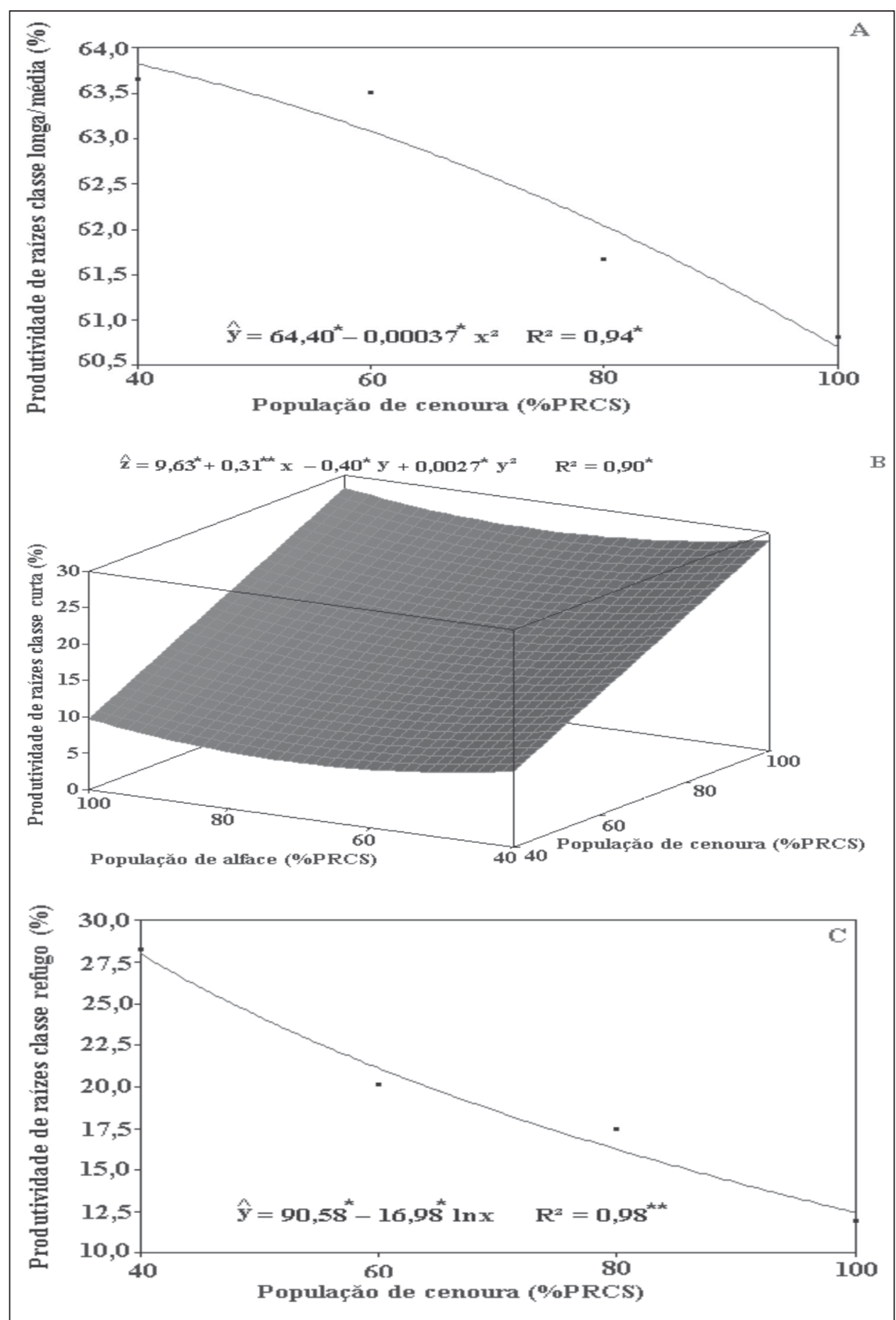

Figura 3 Produtividade de raízes de cenoura (\%) classe longa/média, curta e refugo em função de diferentes densidades populacionais de cenoura e alface em sistema consorciado. Mossoró-RN, ESAM, 2003.

função das densidades populacionais das culturas componentes.

Foi observado um aumento da altura das plantas de cenoura em função do aumento da população de cenoura, atingindo o máximo de $66,11 \mathrm{~cm}$ na população de 100\% PRCS (Figura 1A). Segundo Trenbath (1976), em sistemas consorciados, onde as condições nutricionais do solo são adequadas para o cultivo, a competição por luz é mais intensa, e a utilização de densidades de plantas (Figuras 1B e 1C). A competição intra-específica, causada pela pressão populacional das densidades de cenoura, resultou provavelmente em maior competição pelos recursos ambientais, resultando em redução da massa seca da parte aérea e de raízes de cenoura. Esse comportamento confirma a afirmação de Janick (1968), de que no aumento de densidade populacional de plantas por unidade de área, um ponto é atingido, onde cada planta começa a competir por esses recursos essenciais de crescimento.

Houve uma superfície de resposta para produtividade total e comercial da cenoura em cada variável em função das densidades populacionais de cenoura e alface (Figuras 2A e 2B). Um comportamento quadrático foi registrado na produtividade total em função do aumento da população de cenoura e um linear em função do aumento da população de alface, atingindo o valor de 40,72 t/ha na combinação de $100 \%$ PRCS de cenoura e $100 \%$ PRCS de alface. Para a produtividade comercial também foi observado um comportamento quadrático em função das populações de ambas as culturas, atingindo o valor máximo de 37,13 t/ha na combinação de $100 \%$ PRCS de cenoura e $40 \%$ PRCS de alface. A maior produtividade total e comercial da cenoura, à medida que se aumentou a densidade populacional da cenoura, está diretamente relacionada ao maior número de plantas por área. Estes resultados se assemelham aos encontrados por Minami e Demétrio (1978) em cultivo solteiro, onde eles afirmaram que a causa do aumento na produtividade total e comercial da cenoura em relação ao aumento da densidade populacional da mesma, foi resultante do maior número de plantas por área de solo. Siqueira (1995), estudando o espaçamento de plantio na produção de cenoura 'Brasília' em cultivo solteiro, no município de Mossoró, verificou o mesmo comportamento, no qual ele afirmou que as maiores produtividades totais e comerciais foram alcançadas à medida que se aumentava a densidade populacional da cenoura.

Para a classificação de raízes de cenoura tipo longa/média foi observado uma curva de resposta decrescente com o aumento da população de cenoura (Fi- 
gura 3A). Este comportamento se deve, provavelmente, tanto à competição intra-específica como inter-específica causada pelo aumento da pressão populacional da densidade da cenoura, reduzindo o número de raízes do tipo longa/média. Esse comportamento também é explicado por Coelho et al. (2001), onde eles afirmam que maiores densidades populacionais de cenoura causam redução no diâmetro e tamanho das raízes. Por outro lado, para classificação de raízes de cenoura tipo curta foi observado uma superfície de resposta em função das densidades populacionais de cenoura e alface (Figura 3B). A maior percentagem deste tipo de raízes (29\%) foi obtida na combinação de $100 \%$ PRCS da cenoura e $40 \%$ PRCS da alface. Em relação à percentagem das raízes tipo refugo foi observado uma curva decrescente em função do aumento da população de cenoura (Figura 3C). Para raízes tipo refugo os resultados obtidos são semelhantes aos encontrados por Siqueira (1995) em cultivo solteiro, que ao trabalhar com densidades populacionais menores, determinou um aumento das raízes rachadas, bifurcadas e deformadas.

De maneira geral, não houve interação significativa entre as densidades populacionais de cenoura e de alface em qualquer uma das características avaliadas na cenoura. Não houve também efeito significativo do aumento dos níveis populacionais da alface em qualquer característica avaliada na cenoura. $\mathrm{O}$ aumento na densidade populacional da cenoura aumentou a altura de plantas da cenoura e diminuiu a massa seca da parte aérea e de raízes, e a percentagem de raízes classes longa e média, e refugo. $\mathrm{O}$ aumento na associação das densidades populacionais de cenoura e de alface aumentou a produtividade total e comercial da cenoura, além do aumento na percentagem de raízes classe curta.

\section{LITERATURA CITADA}

BEZERRA NETO, F.; ANDRADE, F.V.; SANTOS JÚNIOR, J.J.; NEGREIROS, M.Z. Desempenho da cenoura em cultivo solteiro e consorciado com quatro cultivares de alface em dois sistemas de cultivos em faixa. Horticultura Brasileira, Brasília, v.19, n.2, julho 2001. Suplemento 2 CD-ROM. Trabalho apresentado no $41^{\circ}$ Congresso Brasileiro de Olericultura, 2001.

COELHO, C.M.B.; CARVALHO, T.D.; LUZ, J.M.Q.; CARVALHO, J.O.M. Adensamento de plantio para produção alternativa de mini-cenoura. Horticultura Brasileira, Brasília, v.19, n.2, julho 2001. Suplemento 2. CD-ROM. Trabalho apresentado no $41^{\circ}$ Congresso Brasileiro de Olericultura, 2001.

FRANCIS, C.A. Distribution and importance of multiple cropping. In: Ed. FRANCIS, C.A. (Ed.) Multiple Cropping, New York: Mcmillan, 1986. p.15-19.

JANDEL SCIENTIFIC. Table Curve: curve fitting software. Corte Madera, CA: Jandel Scientific, 1991. $280 \mathrm{p}$.

JANICK, J. A ciência da horticultura. São Paulo: Livraria Freitas Bastos S. A., 1968. 485 p.
MINAMI, K.; DEMETRIO, C.G.B. Efeito da densidade de população de cenoura (Daucus carota L.) cv. 'Nantes'. Anais da Escola Superior de Agricultura Luiz de Queiroz, Piracicaba, v.35, p.483-490, 1978.

NORUSIS, M.J. SPSS/PC Statistics. Illinois: SPSS Inc., 1990. 320 p.

SALDANHA, T.R.F.C.; NEGREIROS, M.Z.; BEZERRA NETO, F. Cultivares de alface crespa em sistemas solteiro e consorciado com cenoura. In: SEMINÁRIO DE INICIAÇÃO CIENTÍFICA, 7., 2001, Mossoró. Resumos... Mossoró: ESAM, 2001. p.52-55.

SANTOS, R.H.S. Interações interespecíficas em consórcio de olerícolas. 1998. 129 f. (Tese doutorado). - UFV, Viçosa, MG.

SEMENTES SAKAMA. Características de cultivares de alface. São Paulo: Sementes Sakama, 2002. 2 p. (Mimeografado).

SILVA, V.F. Cultivares de alface em diferentes espaçamentos sob temperatura e luminosidade elevadas na região de Mossoró-RN. 1999. $25 \mathrm{f}$. (Tese mestrado) - ESAM, Mossoró, RN.

SIQUEIRA, G.A.S. Espaçamentos de plantio na produção de cenoura "Brasília", no município de Mossoró-RN. 1995. 23 f. (Monografia graduação) - ESAM, Mossoró, RN.

SOUZA, L.C. Componentes de produção do cultivar de algodoeiro CNPA7H em diferentes populações de plantas. 1996. 71 f. (Tese doutorado) UFV, Viçosa, MG.

TRENBATH, B.R. Plant interactions in mixed crops communities. In: PAPENDICK, R.I.; SANCHEZ, P.A.; TRIPLETT, G.B. (Eds). Multiple cropping. Madison: American Society of Agronomy, 1976. p.129-160.

VIEIRA, J.V.; PESSOA, H.B.S.V.; MAKISHIMA, N. Cultivo da cenoura (Daucus carota L.). Brasilia: Embrapa Hortaliças, 1997. 19 p. (Instruções Técnicas, 13).

VIEIRA, J.V.; VECCHIA, P.T.D.; IKUTA, H. Cenoura Brasília. Horticultura Brasileira, Brasília. v.1, n.2, p.42, 1983. 